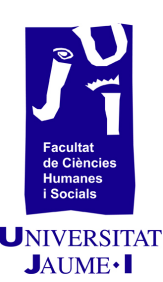

\title{
El papel de la nobleza sarda en el asesinato
}

\section{del marqués de Camarasa}

Carla Torres Llop

al227893@uji.es 
En verano de 1668 acontecen en la ciudad sarda de Cagliari los asesinatos del marqués de Laconi, Agustín de Castellví y del propio virrey de Cerdeña, el marqués de Camarasa don Manuel de los Cobos y Luna. Con estos sucesos llega a su culmen la crisis Camarasa, un episodio que tuvo lugar bajo un clima de inestabilidad política, social y económica en el reino sardo y durante un periodo convulso en el sistema español que coincide con los últimos años del rey Felipe IV y la regencia de Mariana de Austria. El objetivo del presente estudio es analizar cómo el incidente en la isla mediterránea no es sino un reflejo del desequilibrio y la debilidad que se vive en el seno de la monarquía hispánica durante el siglo diecisiete.

Palabras clave: Cerdeña, marqués de Camarasa, marqués de Laconi, parlamento sardo, virreinatos italianos, revueltas nobiliarias, monarquía hispánica, Mariana de Austria, Carlos II.

\section{Introducción}

Don Manuel de los Cobos y Luna, marqués de Camarasa, es nombrado virrey de Cerdeña en 1665 por el rey Felipe IV. A la llegada del marqués la isla se encuentra en unas circunstancias políticas, sociales y económicas de crisis e inestabilidad fruto de la peste que en 1647 la diezmó demográfica y económicamente. El anterior virreinato, el del conde de Lemos, había clausurado el parlamento con los ánimos muy agitados por parte de la nobleza local, que demandaba reformas en las instituciones políticas y más reconocimiento por su lealtad a la monarquía hispánica.

Por su parte, la reina Mariana de Austria actúa al margen de estas peticiones; la Corona no vive su mejor momento como para permitirse ceder a exigencias de un reino como el de Cerdeña. La coyuntura es compleja: la guerra en Flandes, el agotamiento de las tierras castellanas, los problemas sucesorios, las pretensiones de una Francia que parece haber recuperado su poder como potencia europea; por no nombrar los graves problemas económicos que atraviesan las arcas hispánicas y, a la postre, la crispación que se vive entre la corte madrileña y la nobleza local de los reinos, que pronto detonará en forma de motines, como el que nos ocupa: la crisis Camarasa.

El asesinato del virrey y la crisis Camarasa se desarrollan durante los últimos años del reinado de Felipe IV y los años de regencia de Mariana de Austria. En cuanto al estudio de la monarquía hispánica, cabría señalar la imagen burda y simplificada que se presentó durante mucho tiempo sobre el reinado de los últimos Habsburgo 
españoles, en especial de Carlos II. Esta percepción se debe en gran parte a las Memorias (1678-1682) que escribía el marqués de Villars como embajador francés en España. La publicación de Gabriel de Maura (1942), Vida y reinado de Carlos II, contribuyó a desterrar el retrato superficial del monarca "hechizado» fomentado desde el Siglo de Oro.

La elaboración de este artículo surge del interés que despertó en la autora una serie de trabajos sobre los estados modernos italianos para la asignatura Historia Moderna (grado en Historia y Patrimonio). Así pues, se ha desarrollado la investigación en otros trabajos como Doña Francisca de Zatrillas. Por bárbara instigación de una mujer licenciosa, así como otros trabajos en proceso de realización.

\section{Objetivos}

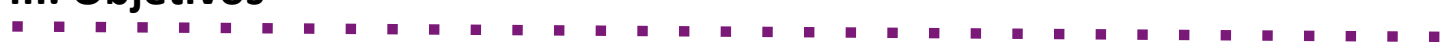

El objetivo de este artículo es analizar el hecho de que las crisis y revueltas que pudieran acontecer en la época en los territorios de la monarquía hispánica no eran otras que el reflejo del desequilibrio político que se produce en la península. Por otra parte, se analiza el asesinato del virrey de Cerdeña, el marqués de Camarasa, como suceso que clausura la crisis que vivía la isla desde hacía años y como antecedente que nos ayuda a interpretar y a explicar la formación de bandos en vista a la guerra de sucesión.

\section{Material y método}

Para acometer los objetivos ya señalados, además de consultar las obras publicadas hasta la fecha, se ha hecho una primera aproximación a las fuentes documentales que se conservan en el Archivo de la Corona de Aragón y en la Biblioteca Nacional.

Se han contrastado dichos materiales para hacer un primer acercamiento dada la poca bibliografía especializada que existe sobre el tema.

\section{Resultados}

La investigación concluyó en las siguientes interpretaciones:

1. La crisis Camarasa es un reflejo de las tensas relaciones entre Corona y estamentos que se dan en el siglo XVII.

2. La Conjura tiene como protagonista a nobles sardos cuyo linaje es originario de la península española (catalanes y valencianos). 
3. La resolución de la sentencia contra los nobles conjurados tiene como consecuencia la renovación de las elites sardas. Este cambio de panorama tendrá fuerte influencia en los proximos eventos que acontezcan en el reino, en especial la guerra de sucesión española y la formación de bandos austracistas y borbónicos.

4. Cerdeña forma parte de la Corona de Aragón tanto como el Reino de Valencia. Esta situación se refleja en la similitud de acontecimientos que suceden en los distintos territorios.

\section{El papel de la nobleza sarda en el asesinato del marqués de}

\section{Camarasa}

\subsection{Marqués de Camarasa, virrey de Cerdeña}

Cerdeña participó de algún modo en la profunda crisis que fragmentó las relaciones entre las clases y la Corona en el reino mediterráneo de la monarquía en el transcurso de la segunda mitad del siglo XVII. No obstante, el único evento violento que desencadenó la desobediencia crónica de los virreyes para con el gobierno central fue el asesinato del virrey Manuel de los Cobos, marqués de Camarasa, caído bajo el golpe de una conjura aristocrática el 21 de julio de 1668. El episodio -en el que se profundizará más delantecausó verdadero desconcierto en la diplomacia española (Anatra, 1997: 27).

Manuel Gómez de los Cobos, marqués de Camarasa, es confirmado nuevamente virrey por la regente Mariana de Austria tras la muerte de Felipe IV (Revilla, 2014: 4). Desde el principio, el marqués encontró un ambiente tenso y poco dado al diálogo en una Cerdeña que, como antes hemos dicho, se encontraba en vías de recuperación después de la crisis económica y demográfica -también social-que había experimentado en la centuria anterior. A este clima poco amigable, hemos de añadirle el carácter de las instrucciones que había recibido de mano de Felipe IV y -más tarde de Mariana de Austria- para su virreinato. Estas disconformidades se ven claramente reflejadas en la correspondencia que mantiene la reina regente con Bernardo Matías de Cervelló, virrey interino en tres ocasiones que hace saber a la reina sus diferencias con el nuevo virrey «habiendo vos llegado a ese Rey [escribe Mariana de Austria a Camarasa] tenía concedidas algunas sacas, de que tocaban los derechos, y que vos se los quitasteis»: no es un secreto que la presencia del marqués de Camarasa no es grata entre los nobles sardos (Revilla, 2014: 4-5). Las instrucciones tenían un carácter más bien autoritario; en la redacción, Felipe IV pretendía seguir la impronta de rey universal que su antepasado Felipe II había llevado a 
cabo en sus dominios. El monarca redactó lo que se esperaba en los años de virreinato de Manuel de los Cobos para Cerdeña con la clara intención de restaurar un poder virreinal fuerte e incuestionable de siglos atrás (Revilla, 2014 b: 578).

Con la muerte de Felipe V, cuando Mariana de Austria se convierte en regente del reino por la minoría de edad de su hijo, el futuro Carlos II, lejos de abandonar esa política tan firme en la isla sarda, la reafirma. El motivo de esta decisión en una coyuntura en la que la diplomacia entre el reino peninsular y el sardo era más bien tensa lo podemos encontrar en el deseo de Mariana de Austria de demostrar la fortaleza del poder real. En un marco histórico bastante cuestionable para España, la reina se niega a que el fidelísimo reino sardo replique, como han hecho otros reinos, la autoridad real (Revilla, 2014a: 4).

A lo largo del siglo, Cerdeña había sido sometida en plena crisis demográfica, después de años de peste, a un esfuerzo humano y financiero sin precedentes que turbó las relaciones fraguadas a lo largo de tantos años (Ribot 2006: 114). La razón de esta sangradura humana y económica eran los donativos a la monarquía aprobados en el parlamento sardo para hacer frente a los múltiples problemas económicos que tenía la Corona fruto de las revueltas surgidas en diferentes puntos de la amplia geografía de España. Para que la aprobación del donativo en los parlamentos fuese posible, entre los siglos $X V$ y XVI se asiste a un restriñimiento del poder pactista de las clases en Cerdeña, lo cual no pasa desapercibido en el seno de las clases sardas (Anatra, 1997: 40):

(...) la Corona punta a un più stretto controllo sulle giustizie delegate, riattivando il processo di razionalizzazione delle strutture burocratiche avviato, nell'area unionista, da Ferdinando il Cattolico, e interrottosi con Carlo V.

Por una parte las fuerzas locales quieren a cambio el control sobre la defensa de la isla: bien sea sobre las estructuras inmóviles como las torres vigía, como sobre las móviles, galeras. Por otra, también exigirán la exclusividad en los oficios burocráticos, reservados siempre a los españoles. En este contexto aparecen figuras de nobles arbitristas que reivindican los intereses sardos. El parlamento de 1654-1656 -también llamado el de Lemos por ser este el virrey- ya se convoca con un espíritu revolucionario y que condiciona la dación del donativo (Anatra, 1997: 30).

\subsection{Parlamento Camarasa}

En su virreinato, el virrey Lemos había logrado poner orden en el parlamento gracias a Villasor que puso «sus votos a libre disposición» a favor de la causa regia (Anatra, 1997: 33). Lo que diferencia al 
parlamento Camarasa de 1666-1668 es que esta vez la facción de la liga fiel a la Corona se presenta minoritaria. El rol importante en la modificación del peso de los dos bandos lo tiene la pequeña nobleza; tanto es así que el virrey, con el apoyo de la reina regente Mariana de Austria, trata de reducir el número de caballeros asistentes al parlamento y prohíbe la asistencia a los «discendientes por linia feminina» (Revilla, 2014a: 4). El parlamento se impregna de un carácter reivindicativo con la facción llamada revisionista encabezada por Agustín de Castelví, marqués de Laconi. El bando Castelví pretende invertir el papel que jugaba la nobleza y clases privilegiadas sardas con corte española: el donativo como condición, no como obligación (Anatra, 1997: 68).

Tras un año negociando en el parlamento, el marqués de Laconi viaja a Madrid para presentar personalmente una serie de reformas. Por su parte, el virrey Camarasa envia a Lupercio Antonio de Molina. A principios de 1668, don Agustín vuelve a Cerdeña sin haber conseguido su propósito, pero con la firme disposición de no ceder a las exigencias del virrey. Llegados a este punto, cabe tener en cuenta que la revisión que se pretende no estriba en los equilibrios sociales, como pasa en Nápoles, sino en las instituciones, como ocurriría en Cataluña (Anatra, 1997: 68-69). La pérdida de espacio para maniobrar por una y por la otra parte provoca, por primera vez, la clausura inoportuna y acelerada del parlamento. ${ }^{1}$ La facción de Laconi se queda sin la mejor baza que tenía para negociar la obtención de sus solicitudes.

A partir de este momento, los acontecimientos se precipitan y se inicia una serie de delitos que ponen el broche final a los conflictos. El 20 de junio de 1668, el marqués de Laconi fue asesinado con uno de sus criados cuando paseaba por la noche (Maura, 1990: 103).

La facción del marqués de Laconi lo presenta como un crimen político, pues, con el asesinato del cabeza de la oposición, todo el partido queda desarticulado. Lejos de rendirse, los revisionistas utilizarán el asesinato del marqués como propaganda política: una herramienta de manipulación para la masa que, desconcertada, culpó de la suerte del "mártir» al propio virrey Camarasa (Revilla, 2014b: 579-580). Por otra parte, la exacerbada propaganda que se hizo del marqués de Laconi desvela a todos los acólitos de la facción: el marqués de Cea, el conde de Montalvo, los marqueses de Albis y de Monteleón, el conde de Villamar y su hermano don Silvestre de Aymerich (Manconi, 2010: 486). Cabe destacar la figura de Pedro Vico, el arzobispo de Cagliari, quien actúa, aparentemente, a favor de los dos bandos. Manconi lo acusa de ser «el mentor oculto de la camarilla nobiliaria contra el virrey» (2010: 487). Revilla también se

\footnotetext{
${ }^{1}$ ACA: leg. 1361, núm. 068, p. 1-4. Debido a las respuestas que obtiene el marqués por parte del Consejo de Aragón, este se ve obligado a clausurar el parlamento por el poco margen de maniobra al que se ve expuesto.
} 
plantea la actuación de este personaje que supo jugar sus cartas tan bien que nunca se pudo comprobar a favor de quién realmente había obrado (2014a: 1-16).

Laconi es presentado como el "padre de la patria» y en torno a él se construye un verdadero símbolo nacional. Manconi inculpa directamente al arzobispo acerca de la delineación del imaginario colectivo alrededor de la figura de Agustín de Castelví (2010: 488). Visto el clima prerrevolucionario que hay en la isla, el virrey empieza a temer por su vida. El 21 de julio de 1668, tan solo un mes más después del asesinato de Laconi, cuando el marqués virrey volvía a casa con su familia, atentaron contra él a carabinazos hiriéndole de muerte:

(...) dicho marqués de Camarasa siendo virrey capitán general de este reyno al qual subiendo y retornando del convento de Nuestra Señora del Carmen y de la fiesta que se celebraba en su octabario, mataron alebosamente de carabinazos el sábado 21 del mes de julio de dicho año de 1668 dentro de su coche y en el estrivo que tenía con su mujer e hijos disparándole a las siete y media de la tarde des de una ventana y reja de madera que esta en la calle que llaman de Cavalleros de la Casa de Antonio Brondo que tiene por la cavalleris de esta calle por donde entraron los facinerosos transgresores con mucha comitiva de gente armada de armas probitorias. $^{2}$

\subsection{Sentencia contra Francisca de Zatrillas, marquesa de Sietefuentes ${ }^{3}$}

Tanto en la corte virreinal como en Madrid, durante días cundió el miedo a una sedición protagonizada por los nobles sardos. ${ }^{4}$ Mariana de Austria nombró como nuevo virrey al duque de San Germán, Francesco Tutavilla, un militar con amplia experiencia en el frente extremeño en la guerra contra Portugal que había demostrado su fidelidad a la Corona por medio de un dilatado expediente de servicios a la monarquía, además de su experiencia como virrey de Navarra (Revilla, 2014a: 9-16). A él fueron encomendadas instrucciones muy precisas: encontrar a los culpables. Así se abre un nuevo proceso criminal por la muerte de los dos marqueses que acaba con la sentencia contra la esposa del marqués de Laconi, doña Francisca de Zatrillas, marquesa de Sietefuentes.

Los informes del proceso dicen así:

Tubieron muchas Juntas en casa de doña Francisca Zatrillas y Castelví ella con Silvestre Almeric, con don Jaime Artal de Castelví

\footnotetext{
${ }^{2}$ BNE, Mss/18055. p. 679-680. Sentencia sobre la muerte violenta de D. Agustín de Castelví, marqués de Laconi.

3 Para profundizar en la cuestión, consultar TORRES LLOP, Carla (2016): Doña Francisca de Zatrillas. Por bárbara instigación de una mujer licenciosa. Castellón de la Plana: Universidad Jaume I.

${ }^{4}$ Véase ACA: leg. 1049, p. p. 878-879.
} 
marqués que fue de Cea, don Antonio Brondo, don Franciso Cao, don Francisco Portugués, don Gavino Grixoni y otros para matar al dicho ilustre marqués de Camarasa virrey, y para ejecución de tan malvada determinación [...] se fulminó proceso produciendo muchos testigos falsos por fuerza para que constase que la muerte del marqués de Laconi fue hecha de la orden de la ilustre marquesa de Camarasa con ciencia del ilustre marqués de Camarasa su marido. $^{5}$

Señala los nombres de los culpables, pero se cuida de no señalar al propio Agustín de Castelví como también instigador del asesinato del virrey. Los nobles arriba nombrados se refugiaron al norte de la isla, en los territorios de Logudoro y Monteacuto, donde el marqués de Cea y sus acólitos gozaban de fuertes lazos feudales y contaban con el apoyo y la protección de sus vasallos. Para derrotar al marqués de Cea y al resto de sus aliados, el virrey Tutavilla confió en los bandoleros de Gallura. Finalmente, tras una puntual fuga a Francia, los nobles son apresados en las costas del norte cuando regresaban de nuevo a Cerdeña. A todos se les aplicó la pena de muerte por un delito contra lesa majestad (Manconi, 2010: 496). Con este episodio se demuestra que tanto las relaciones feudales como el apoyo en bandoleros por parte de la nobleza local no eran tan solo un acto recurrente en el Reino de Valencia (Catalá, 1996: 155-172). A todos ellos se les sometió a una represión despiadada de forma individual, no socialmente; es decir, el castigo se aplicó solo contra las personas que participaron en el magnicidio, no contra la nobleza o el pueblo sardo como tal. "Así mismo ordenó el virrey duque de San Germán demoler sus casa, pasar arado y sembrar sal por el solar y conservar las ruinas» (Revilla 2015: 17). Los partidarios de Laconi, por su parte, responsabilizaban de esta crisis al contrato entre los estamentos y la Corona en la clausura del parlamento de Lemos (Anatra, 1997: 57).

\subsection{Conclusiones}

Lo ocurrido en el proceso parlamentario Camarasa es la consecuencia de años de tratar de camuflar tensiones entre la feudalidad sarda y la Corona española. Deben analizarse los factores que impidieron el éxito de la conjura. Ante todo, cabe señalar el origen "mestizo» de las clases nobiliarias sardas cuyas raíces se encontraban en los reinos peninsulares de Aragón y, sobre todo, de Cataluña y de Valencia. Estos lazos familiares potenciaron en mayor medida el sentimiento familiar que el nacional entre las casas de Cerdeña. Por otra parte, se encuentra el factor de la gente: la conjura es al cien por cien nobiliaria, los intereses, las demandas al parlamento, etcétera, son enunciadas y dirigidas por y para la clase

\footnotetext{
${ }^{5}$ BNE: Mss/11017 p. p. 193-194. Sentencia contra doña Francisca Zatrillas, marquesa de Laconi.
} 
noble. En este acto elitista, marginan al resto de las clases sociales con lo que se vuelve casi imposible que triunfe un golpe nacionalista. Por último, pero no por ello menos importante, subyace la paradójica situación de la nobleza: saben que no pueden sostenerse sin el apoyo de la monarquía hispánica. Esta es la que les concede las mercedes y las gracias, que -si bien modestas- son vitales para la economía de las familias nobles en Cerdeña.

La crisis Camarasa no es más que un episodio tardío de la crisis que estaba atravesando el "sistema de poder» español, en el curso del cual la clase dirigente sarda no aparece en ningún punto como la que asume el arbitrio de su libertad, que solo se demuestra en momentos puntuales y violentos. Tanto es así que para restablecer el orden solo hizo falta recorrer a las milicias isleñas. Si se puede concluir algo de esta crisis es que cuando la baronía actúa más por la mecánica de los acontecimientos que por elección consciente pone en peligro la lealtad tradicional para con la monarquía, pierde uno de sus puntos de apoyo y «si ritrova nella classica situazione del giganti dai piedi di argilla» (Anatra, 1997: 35-36).

No obstante, la resonancia real que tuvo el evento fue más allá de la represión de algunos de los nobles más distinguidos del reino. Llegados a este punto, se analiza cuál fue -al margen de las medidas que se tomaron inmediatamente después del magnicidio contra los responsables- el motivo por el cual el episodio investigado tiene tanto peso en la historia de Cerdeña y en la de España. Con la persecución y ejecución de los nobles acusados de haber participado en la conjura y el asesinato del marqués, quien no se exilia, muchos de los puestos en la administración de Cerdeña quedan libres. Hay que tener en cuenta que los conjurados pertenecían a la más alta alcurnia del reino insular que eran ellos los que habían gozado del beneplácito real durante años de forma que habían obtenido para sí los mejores puestos en las instituciones de la monarquía hispánica. Con esto, muchos nobles y burgueses tendrán la oportunidad de promocionarse hacia puestos de mayor responsabilidad. Llegados a este punto, ha de reconocerse el papel social y político que juega la nobleza emergente a partir de este momento. Por supuesto, estos «nuevos nobles» se declararán fieles a la Corona. Esta lealtad se verá revalidada durante la guerra de sucesión con una obvia militancia austracista.

Por su parte, la antigua nobleza tendrá -como ya se había citado- la oportunidad de reafirmarse en su lealtad a la Corona aportando tercios y apoyo militar durante la revuelta de Mesina. Algunos, como los marqueses de Villasor, reclamaron reconocimiento por haberse mantenido fieles al monarca a pesar de la coyuntura. Cuando muere el rey Carlos II y estalla la guerra de sucesión, los nuevos nobles que habían obtenido su puesto a raíz de la crisis Camarasa representarán la facción austracista, mientras que 
los nobles sardos exiliados o procesados por la justicia de la corte apoyarán la causa borbónica.

Pasado este acontecimiento, en 1678 y hasta fin de siglo, se reactiva la praxis parlamentaria con el normal suministro del donativo, si bien no se abandonan las peticiones que habían caracterizado el periodo precedente (Anatra, 1997: 57-59). Hasta aquí la tentativa, aparentemente ingenua, de acuerdo con su hábito político, por parte de la baronía partidaria de restaurar lealtad con el monarca y su corte a los que se tiene sólidamente avenida la facción de los Villasor. Los hombres que, diez años más tarde, tuvieron ocasión de resarcirse con la revuelta de Mesina y la "provisión del tercio de Sardos que llevó a Sicilia» (Anatra, 1997: 36).

\section{Fuentes documentales}

\section{Fuentes manuscritas}

Biblioteca Nacional de España:

Mss/11017, p. 193-196 Mss/18176, p. 194-207, 207-214 Mss/ 18055, p. $678-686$

Archivo de la Corona de Aragón:

Consejo de Aragón: legajo, 0584, no 036. p. 1-20 Consejo de Aragón: legajo, 1362, no 001. p. 5-234 Consejo de Aragón: legajo, 1361, no 068. p. 1-4 Consejo de Aragón: legajo,1049. p. 878-879

\section{Fuentes impresas}

Salazar y Castro, Luis, 1694. Historia genealógica de la Casa de Lara. Justificada con instrumentos y escritores de inviolable fe. Tomo I. Madrid.

\section{Bibliografía}

Alcalá-Zamora, José (ed.). 2001. «Lenguajes y oídos en La vida es sueño». En Calderón de la Barca y la España del Barroco, coordinado por José Alcalá-Zamora y Ernest Belenguer Cebrià, vol. 2, 863-869. Madrid: Centro de Estudios Políticos y Constitucionales.

Anatra, Bruno. 1997. Instituzioni e società in Sardegna e nella Corona d'Aragona (sec. XIV - XVII). El arbitrio de su livertad. Cagliari: AM\&D Edizioni. 
Arce, Joaquín. 1960. España en Cerdeña. Aportación cultural y testimonios de su influjo. Madrid: Consejo Superior de Investigaciones Científicas. Instituto Jerónimo Zurita.

Casey, James. 1983. El Reino de Valencia en el siglo XVII. Madrid: Siglo XXI.

Catalá Sanz, Jorge Antonio. 1996. «Consideraciones sobre el desenlace del proceso de pacificación de la nobleza valenciana». Studia Historica, Historia Moderna 14: 155-172.

Corona Marzol, Carmen. 2007. "Las Instituciones políticas en la Corona de Aragón desde sus orígenes al reinado de Carlos II». En Historia de la Corona d'Aragó, editado por Ernest Belenguer, 7394. Barcelona: Edicions 62.

-. 2003. «Pretendido neoforalismo de la Corona de Aragón. De los reinos de Aragón, Valencia y el principado de Cataluña». En Calderón de la Barca y la España del Barroco, coordinado por José Alcalá-Zamora y Ernest Belenguer Cebrià, vol. 1, 1027-1059. Madrid: Centro de Estudios Políticos y Constitucionales.

Fernández Nadal, Carmen María. 2009. «Felipe de Egmont, virrey de Cerdeña (1680-1682): el final del camino». Millars: Espai $i$ Història 32: 143-162.

-. 2015. «El poder de una red femenina. Familias, vida y muerte de Luisa Velasco (siglo XVII)». Millars: Espai i Història 38: 57-91.

Firpo, Luigi. 1979. «Spagna». En Relazioni di ambasciatori veneti al Senato. Vol. X. Turín: Bottega d'Erasmo.

-. 1965-1984. Relazioni di ambasciatori veneti al Senato, tratte dalle migliori edizioni disponibili e ordinate cronologicamente. Turín: Bottega d'Erasmo.

Galasso, Giuseppe. 2003. "L'Italia spagnola alla metà del secolo XVII». En Calderón de la Barca y la España del Barroco, coordinado por José Alcalá-Zamora y Ernest Belenguer Cebrià, vol. 1, 873-887. Madrid: Centro de Estudios Políticos y Constitucionales.

Guía Marín, Luis. 2012. Sardenya, una història pròxima. Catarroja: Afers.

Lio, Salvatore (2008): "La inquisició espanyola a Sardenya. Un tribunal gairebé oblidat». En El regne de Sardenya a l'època moderna. Afers: fulls de recerca i pensament, editado por Francesco Manconi, 59 (23): 91-106.

López Cordón, María Victoria. 2009. «Mujeres en la vida de Carlos II. La reina que nunca fue niña y el príncipe encantado». En Carlos II. El rey y su entorno cortesano, editado por Luis A. Ribot. Madrid: Centro de Estudios Europa Hispánica.

Lynn, John A. 2013. The Wars of Louis XIV 1667-1714. Hoboken: Taylor and Francis. 
Mafrici, Mirella. 1995. Mezzogiorno e pirateria nell'età moderna (secoli XVI-XVIII). Napoli: Edizioni scientifiche italiane.

Manconi, Francesco. 1999. "La peste en Cerdeña a mediados del siglo XVII. Cuestiones demográficas y sociales». Obradoiro de Historia Moderna 8: 121-134

- 2010. Cerdeña. Un reino de la Corona de Aragón bajo los Austria. Valencia: Publicaciones Universidad de Valencia.

—. 2007. «El regne de Sardenya: de Ferran el Catòlic al Decret de Nova Planta». En Història de la Corona d'Aragó. L'època moderna (1479-1715) Ferran II i els Àustria, editado por Ernest Belenguer, vol. II, 397-447. Barcelona: Edicions 62.

—. 2008. «El regne de Sardenya a l'època moderna. L'empremta catalana». En El regne de Sardenya a l'època moderna. Afers: fulls de recerca i pensament, editado por Francesco Manconi, 59 (23): 9-19.

—. 2008. «El regne de Sardenya a l'època moderna». En El regne de Sardenya a l'època moderna. Afers: fulls de recerca i pensament, editado por Francesco Manconi, 59 (23): 107- 122

Mateu Ibars, Josefina. 1964. "Virreyes durante el reinado de Carlos II». En Virreyes de Cerdeña: fuentes para su estudio, editado por Josefina Mateu Ibars, cap. X. Milán: CEDAM.

Maura, Gabriel. 1990. Vida y reinado de Carlos II. Madrid: Aguilar.

Molas, Pere. 2010. "Virreyes italianos en la Corona de Aragón». En Centros de poder italianos en la monarquía hispánica (siglos XVXVIII), editado por José Martínez Millás, vol. I, 37-43. Madrid: Marcial Pons.

Novo, José R. 2009. "La Casa real durante la regencia de una reina: Mariana de Austria». En Las relaciones discretas entre las monarquías Hispana y Portuguesa: las casas de las reinas (s. XVXIX), editado por José Martínez, vol. I, 483-548. Madrid: Polifemo.

Parker, Geoffrey (coord.). 2006. La crisis de la monarquía de Felipe IV. Barcelona: Publicaciones del Instituto Universitario de Historia Simancas, Universidad de Valladolid. Libros de Historia.

Revilla Canora, Javier. 2015. «Tan gran maldad no ha de hallar clemencia ni en mí piedad. El asesinato del Marqués de Camarasa, Virrey de Cerdeña, 1668». Revista Escuela de Historia 12

http://www.scielo.org.ar/scielo.php?script=sci_arttext\&pid=S16 69-90412013000100005.

-. 2014a. Jaque al virrey: Pedro Vico y los Suçesos de Zerdeña durante la regencia de Mariana de Austria. Monográfico 1, año 6. Acceso de junio de 2015. Librosdelacorte.com. 
-. 2014b. El asesinato del virrey marqués de Camarasa y el pregón general del duque de San German (1668-1669). Madrid: Universidad Autónoma de Madrid.

Ribot, Luis A. 2003. La presencia de a Monarquía de los Austria en Italia a finales del siglo XVII. En Calderón de la Barca y la España del Barroco, coordinado por José Alcalá-Zamora y Ernest Belenguer Cebrià, vol. 1, 975-995.

-. 2006. El arte de gobernar: estudios sobre la España de los Austria. Madrid: Alianza.

-. 2009. Carlos II y su entorno cortesano. Madrid: Centro de Estudios Europa Hispánica.

Rivero, Manuel. 2011. La edad de oro de los virreyes: el virreinato de la monarquía hispánica durante los siglos XVI y XVII. Madrid: Akal.

Storrs, Christopher. 2006. The Resilience of the Spanish Monarchy 1665-1700. Nueva York: Oxford University Press.

Torres, Xavier. 2008. «El bandolerisme a Sardenya. Una visió comparativa». En El regne de Sardenya a l'època moderna. Afers: fulls de recerca i pensament, editado por Francesco Manconi, 59 (23): 107-122.

\section{Recursos web}

Fundación Medinaceli: fundacionmedinaceli.org [septiembre, 2015] 